\title{
A note on names and orthography
}

Writing on African history requires choices regarding nomenclature and orthography. Selecting and imposing names and ways of writing them, in fact, belonged to the exercise of colonial power over language. When the Belgian Congo became an independent country, African politicians and scholars began to restore traditional names and, in many cases, to introduce innovations appropriate to symbolize the end of colonial rule. This is legitimate even if it disturbs geographers and bibliographers. However, to employ current names would make it necessary constantly to refer to earlier usage (which, needless to say, did not remain unchanged from 1880). So as to keep confusion within bearable limits, I have adopted place and other names, as well as their transcription, as they occur in the sources and during the period treated in this study. No political offence is intended, therefore, when I write Congo instead of Zaire, Elisabethville for Lubumbashi, Katanga for Shaba, Tanganyika for Tanzania, and so forth. Ethnic terms and names for languages are most of the time rendered without prefixes unless such a modification is distinctive (as in Tshiluba and Kiluba, varieties of Luba in the Kasai and in Katanga respectively). Language quotations from printed and manuscript sources are always as in the original. Their inconsistencies and linguistic deficiencies often contain precious information. 
This page intentionally left blank 